\title{
Smart insects repeller
}

\author{
Suzi Seroja Sarnin, Nur Jumaatul Hidayati Binti Mohammad, Nani Fadzlina Naim, \\ Norsuzila Ya'acob, Azlina Idris, Wan Norsyafizan Wan Mohamad, Mohd Nor Md Tan \\ Faculty of Electrical Engineering, Universiti Teknologi MARA, Malaysia
}

\begin{abstract}
Article Info
ABSTRACT

Article history:

Received Apr 30, 2019

Revised Jul 22, 2019

Accepted Aug 5, 2019

One of the key issues for those involved in farming and greenhouse is the use of pesticides. In a recent headline, there has been an epidemic of insect infestation that has destroyed 211 hectares of rice plants. These concerns have led to the discussion of possible over-use of pesticides that are not just killing dangerous pests, but also other animals that help combat the pest. In order to overcome the problem, a research was conducted by introducing a smart insect killer. In this developing project, Pyroelectric (PIR) sensor will be using as a motion detector towards insects. This sensor plays a role to transmit the signal for action in taking care of the plant. The IR sensors will install around the plant, so that it has good range to detect any motion. As a result, suitable chemical spray will trigger to repel these insects. A light emitting diode as an indicator of functional to the system. "Smart Insect Repeller" will work when certain pests are detected and this will reduce the use of poisons and the quality of the crop will be preserved due to the use of minimal poisons.
\end{abstract}

Copyright () 2020 Institute of Advanced Engineering and Science. All rights reserved.

\section{Corresponding Author:}

Suzi Seroja Sarnin,

Department of Electrical Engineering,

Universiti Teknologi MARA,

40450 Shah Alam, Selangor, Malaysia.

Email: suzis045@uitm.edu.my

\section{INTRODUCTION}

Agriculture is the cultivation and breeding of animals, plants and fungi for food, fiber, biofuel, medicinal plants and other products used to sustain and enhance human life [1]. Agriculture was the key development in the rise of sedentary human civilization, whereby farming of domesticated species created food surpluses that nurtured the development of civilization. The objective of this project is to design a control of pest and insect repellent in scope of greenhouse. Main target in this project is pest that always damaging crop plant such as pepper plant. The example of pest that always damage the pepper plant such as locusts, lady bird and caterpillars. So, this project is to apply the pesticide automatically in order to protect the plant from any other insects. Therefore, by using the pesticide, it will help to reduce the presence of insect or pests but also may give bad effect on the plant itself and user that consuming it. So that why in this project use the specific sensor to detect the pest only and will not harm other than that. The excessive usage of the pesticide will affect the ecosystem and also to the society. By designing and inventing this smart insect repellent, it will achieve the purpose of using the pesticide and also consume less the usage of the pesticide. The water level sensor also will be put at the container of pesticide to notice farmer about the quantity of pesticide remaining This method can help in less using of human energy and costing for hiring the worker.

In agriculture plants crop, it need an additional substances apply towards plants. With this substance, plants crop can be maintain its fertility and grow in healthiness as well as produce high quality outcomes. This substance or commonly behave as biological agent is Pesticides. Pesticides is categorized in few type which are Herbicides, Insecticides, Fungicides and Rodenticides. Different name bring different what type of resistance occur. In Malaysia, amount budget of pesticides used increased in 1995 to 2008 with 
increased of $31 \%$. Herbicides used the most with $76 \%$ apply [2]. Among most of pesticides, fungicides is frequently used in many plants [3].

Moreover, this issue almost happened everywhere and have become common matter to give attention and need an action. Without serious action, it will affect on every corner. In economic losses, some of it due to pests and diseases in fruit came from plants. Some researcher found for pests resistance, not only specifically insects are involved, and in fact, insects contribute less than others [4].

So, In this case, this project mainly focused on insects that happen turns to insects attack. The clear reason to grow vegetables, flowers and herbs in greenhouse is to have crops at a time of year when it can't grow outdoors. Growing vegetables in greenhouse brings many benefits. However, there also several problems that missed out through the process of growing. These are the list of a few problems that mostly occur. Firstly, pests are very common behave act to eat or damage the plants. There are many types of pests that usually give problem to vegetable plants. Commonly it called Garden Pests. Moreover, any plants need healthy condition in order to produce fruit at good shape and out of diseases. Besides taking care the fertility of soil, the condition of the fruit need to be maintain too.

Nakayama implied the usage of the motion detection to detect insect. Benefit in using the motion detection is it can detect object quickly and effectively. But the con is that it cannot control the instruction which sensor detect. If the motion sensor detected an object whether it is insect or other thing, it will give instruction to the microcontroller to continue next instruction [5]. In addition, this project plan to design a system with health care on plants crop. Skolnik stated that insects also can be detected by various groundbased radar installations and their dispersal tracked by continually monitoring the coordinates of radar echoes from the insect targets [6]. Which refer to organic pesticides spray. Lastly, the aim is to design a system with helpful database in applying into research and development

Within the process to be done in this project, few researches need to look forward. What things that include are the previous researcher who have made their experiment towards the concept of project which might came with positive or negative outcome. Within this section, many research papers which gain inspired and become a guidance to develop this research. Monitor and control are one of the main features throughout the research. Sandeep Gaikwad, Arun Gaikwad, Rajesh Harsh and Anurag Gupta has proposed that the Simulation Modeling and Implementation RF and MW System to Control the Insects Pest in Agriculture [7].

Research paper on keeping quality of Agriculture by Brendan O'Flynn, Marco De Donno, Colm Barrett, Caoimhe Robinson and Alan O Riordan from University College Cork in Ireland, Smart Microneedle Sensing Systems for Security in Agriculture, Food and the Environment (SAFE). This team were using low power consumption, smart microneedles and wireless communication embedded system on security applying on agriculture system [8]. This project were applying Nanotechnology which enables efficiency of water, pesticides and fertilizers on agriculture sector. Secondly, research paper on agriculture application project by J.L.E. Honrado, D. B. Solpic, C. M. Favila, E. Tongson, G. L. Tangonan, N. J. C. Libatique from Manila University in Pihilipines, UAV Imaging with Low-cost Multispectral Imaging. The mission is to monitor in rice and corn field using aerial imaging which function as calibration points for extending the measurements over the whole image field [9]. This project implemented an Unmanned Aerial Vehicle (UAV) to run the experiment on agriculture sector. The objective proposed to improve on monitoring and managing regional agriculture.

According to other researcher which are Zhang, Hongtao, Hanping Mao, and Daoyin Qiu, they conduct their research using insect detection system based on image recognition technology [10]. In their research, they extracted seven features that composed of the optimal feature space from 17 morphological features such as area and perimeter of the insect. This way of insect detection is very complex to imply as it uses many features extraction of the insect. Also, one of the disadvantages in this research is only limited species of insect. This method uses complex calculation and many features are used in detecting the insect. So, only particular insect that been specified in this research only work for the insert detection. For the advantage of this technique, this based recognition technology is practical and feasible which also have $95 \%$ correct identification ratio. So, this mean that the insect that have been detect have high possibilities to be correct insect.

Next related paper Smart E-Agriculture Monitoring System by Juthi Kundu, Supriya Debi, Saleh Ahmed, and Sajal Halder. This research paper provides a platform to the farmers in e-marketing to avoid any cheater between distributors and farmers, so that there is fair price towards their product [11]. Moreover, system which proposed will calculates the total cultivated amount of agricultural product so that it can be cleared to all about country's agriculture production, find out how much goods have stored by nongovernment agent and how much agricultural goods can be export after fulfilling the country's needs. Pesticide is well known pest and insect repellent that can give disadvantage when it used excessively. The architecture must be flexible and adaptive in order to be used in wide range of applications. In addition, for cost reasons it must make it easy to assemble just the right set of software and hardware components. 
Okayasu, Nugrobo, Sakai, Arita, Yoshinaga, Taniguchi, Horimoto, Inoue, Hirai and Mitsuoka suggest in their research on Affordable Field Environmental Monitoring and Plant Growth Measurement System for Smart Agriculture [12]. This method can improve agricultural production in terms of advancing the knowledge and techniques of farming, reducing production costs, and improving the quality of agricultural produce.

Proceed to next research paper by Takashi Okayasu, Andri Prima Nugrobo, Atsushige Sakai, Disaku Arita, Takashi Yoshinaga, Rin-ichiro Taniguchi, Masafumi Horimoto, Eiji Inoue, Yasumaru Hirai and Muneshi Mitsuoka, Affordable Field Environmental Monitoring and Plant Growth Measurement System for Smart Agriculture [13]. Within this paper, an affordable field environment monitoring and plant growth measurement system in smart agriculture is introduced. This design and development of low-cost field environmental monitoring system is explained and then its ability is verified by a real field test. Moreover, system which proposed will calculates the total cultivated amount of agricultural product so that it can be cleared to all about country's agriculture production, find out how much goods have stored by nongovernment agent and how much agricultural goods can be export after fulfilling the country's needs.

Continues with the research paper about implied the UAV imaging with Low-cost multispectral training [13]. Their research is to monitor rice and corn filed using aerial imaging which functions as calibration points for extending the measurement over the whole image field. The research was able to improve monitoring and managing regional agriculture which also can maintain the quality of the plant. But the implementation of the UAV imaging is very high budget and possible for the computer software to breakdown.

Next, research paper about A Survey of Smart Agriculture IoT with Cloud Computing. Developing a project on agriculture using Internet of Thing (IoT) technologies which can control the cost, maintenance and monitoring performance [14]. In this paper described the understanding different technologies and how to build sustainable smart agriculture using simple IoT with a wireless network. By applying a microwave heating on tomatoes plant and with harmful insect pest, showed that it can suppress any insects from any plants.

Hill stated that one of the solutions is to combine together events from multiple sensor nodes by a local group of nodes and then transmit a single result across the sensor network [15]. The pyroelectric sensor is actually divided into two halves. When there is no motion, both halves receive the same amount of IR radiations from the surrounding [16] . Based on Atsushige, Takashi Okayasu, Takasyi asu, Takasyi Oshinaga, Masafumi and Yasumaru, they said that nowdays various affordable sensors and devices have been developed and utilized in a wide area sector. So, they need to apply something to improve agriculture production in terms of advancing the knowledge and technique of farming, reducing production costs, and improving the quality of agriculture produce [17]. Regardless of the hierarchical approach each device, as part of Internet of things, still needs a program, and the most common approaches to programming each smart device, is to either program it using some form of operating system or to choose a higher level of abstraction. The operating systems vary from traditional operating systems in terms of goals and technique and each system differs substantially in the approach to memory protection, dynamic reprogramming, thread model, real-time features [18].

Generally, this paper presents about smart insects repeller by making an intelligent hardware that able to detect pests on every plants which keeping in greenhouse. This project will run using a Pyroelectric Infrared (PIR) Sensor. This sensor will allow to sense motion, whether a humans or objects which has moved in or out of the sensors range. This particular sensor usually applied on human detector project. But, in this project, it will be implement on agriculture which is on plant. The whole hardware will place at the angle where the plant is planted. From the angle, the IR sensors can detect any movement . Insects will be trapped by using chemical spray, after the motion sensor is triggered. Light Emitting Diode (LED) and buzzer will operate. Thus, analysis have been made on several previous research papers related to this project concept.

\section{RESEARCH METHOD}

The overall process of how the system works are showing in Figure 1. In hardware section, long brief given on what the system made of and how it can relate with the project title. The details below are including hardware and software that will be implementing in the project. Throughout this project, this idea of designing and building a smart pesticide control is came up after the study of the usage of the pesticide. However, the strength of any device is its flexibility and universality. One of the great things about the Raspberry $\mathrm{Pi}$ is that it is very flexible and there's no single way to use it. For example, it can be used for general purpose such as computing, learning to program or integrate it with electronics projects. So, by this problem, this study will able to help to reduce the usage of the pesticide and increase the quality of plant by repelling the insect and pest. This study is focus on developing a control in usage of the pesticide using 
Raspberry Pi microcontroller would be compose of major components such as Raspberry Pi microcontroller, motion sensor, sprayer, motor and LED. All the components will be adopted in completing this study.

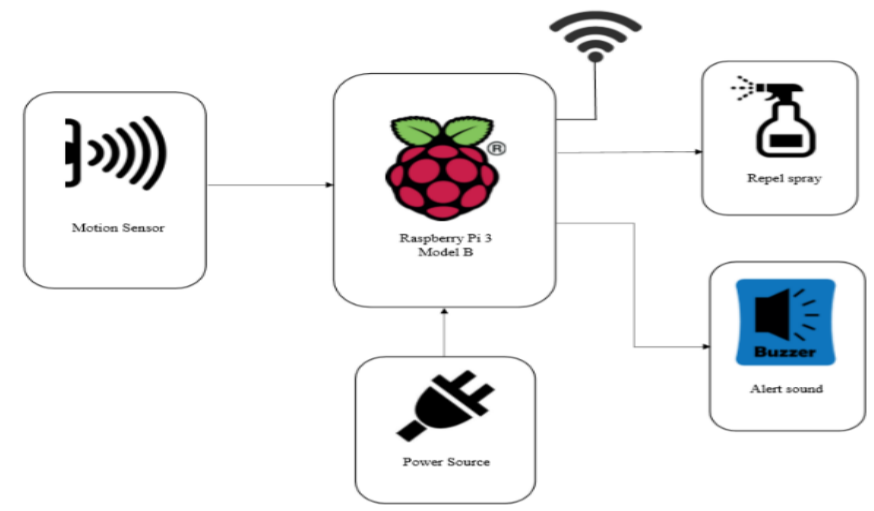

Figure 1. Overall system with elements involved

\subsection{Flowchart}

Flow chart in Figure 2, shows how the system running. The process need to take time before the motion sensor can capture pests.

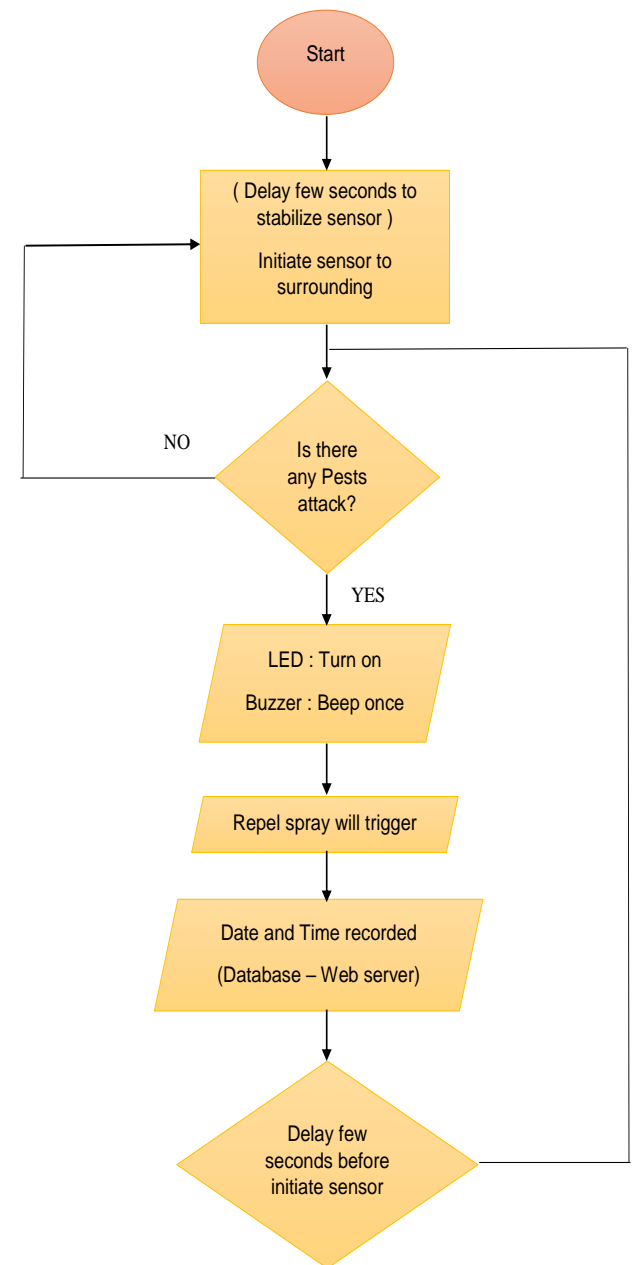

Figure 2. Flowchart system 
Pyroelectric Infrared sensor need to stabilize first as a warm up. Then, the sensor will wait until the subject pest is pass through. Next, LED will turn ON, to indicate those plant crop have been disturbed. The buzzer will beep later on, followed by spray mechanical. Data of date and time will be record and transfer to database through web server.

\subsection{Hardware Specifications}

\subsubsection{Raspberry Pi 3 Model B}

Main component and biggest influence to the project is Raspberry Pi. This system is using latest version which is Raspberry Pi 3 Model B. Raspberry Pi are a tiny single-board computer which can be used for robotics, commercial and industrial produc [18]. With an upgraded processor boasting impressive new packaging and improved networking capabilities, the new Raspberry Pi 3B+ sits head and shoulders above its predecessor the Raspberry Pi 3. The Raspberry Pi is a series of small single-board computers stamped with chips and I/O connectors. This board built in with WiFi and Bluetooth features which will send a signal/notification to android Smartphone and Laptop. Raspberry Pi provides greatest features to user, which able to install many applications within the system. These features will make certain project full of creativity and increase functionality. It operates in the same way as a standard PC, requiring a keyboard for command entry, a display unit and a power supply. The Raspberry Pi is chosen as the microcontroller as it has better performance than any other microcontroller.

\subsubsection{Pyroelectric Infrared (PIR) Sensor}

Next component of a PIR sensor is the pyroelectric sensor which is present behind the plastic. An infrared sensor is an electronic instrument which is used to sense certain characteristics of its surroundings by either emitting and/or detecting infrared radiation. Infrared sensors are also capable of measuring the heat being emitted by an object and detecting motion. .In this project, the infrared is related to long-wavelength infrared type $\left(89--80^{\circ} \mathrm{C}\right)$. The sensor can obtain a completely passive image of objects if only it temperature a little bit higher than room temperature $\left(32^{\circ} \mathrm{C}\right)$ which consider as "thermal imaging" region or "thermal infrared". However, when a target crosses the sensor, the IR radiations level received at one half is more than the radiation at other half. The PIR reacts to this change and makes the output HIGH. The range of detection goes up to 6 meters, and it takes some time to stable itself according to the surrounding when it is powered ON. When any pests are passes through the PIR sensors, it will keep the value and send to Raspberry Pi [19].

\subsubsection{Buzzer}

Buzzer act as a indicator in this system. Sound producer installed able to notify to workers at surrounding [20]. This buzzer help farmers whose at surrounding crop plant able to check and monitor the plant that has been disturbed.

\subsubsection{Motor (Spray Mechanical)}

DC motor that installed in this project act as mechanical to trigger spray organic. Few gears are assembled onto the body of motor to help flow of mechanical. The application in agricultural areas is of prime importance for crop yields [21].

\subsection{Software Development}

In this section, few things relate with software implementation will be explain. Software will lead towards hardware operation. Coding that was built need to synchronize with process of project such as [22].

Figure 3 shows the coding of PIR sensor interfacing with other components. In short review, PIR sensor as it is behavior need to warm up few seconds to operate. So, in the beginner of coding, 20 seconds time sleep is set to fulfill sensor's behavior.

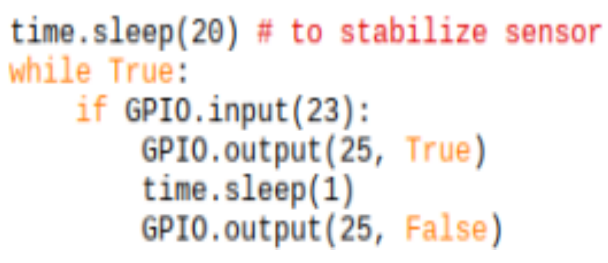

Figure 3. Short coding of motion sensor 


\section{RESULTS AND ANALYSIS}

At the end of this project, a complete system of pest control should be anticipated to be work functionally. This prototype will be will control the usage of the pesticide and also repel any insect or pest that can affect the growth of the plant in the greenhouse. This system also able to differentiate the motion of insect or pest with other motion that is bigger. The sensor will detect the motion and identify the detected object to trigger the sprayer. In this project, expected results will produce 2 output which are mechanical spray system and buzzer. As a prove of the results, project coding is showing in this part. Inside the coding, every step of the system running precisely indicated. Coding are running in Python software which installed already in Raspbian (Raspberry operating system). Python is considered an "interpreted language," which means that project developer can write a program or script and execute it directly rather than compiling it into machine code. This what makes the process easier and efficient. Figure 4 shows a proven results which works in a simulation software.

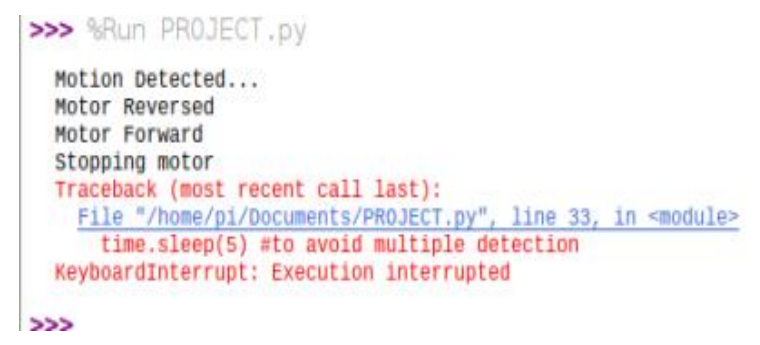

Figure 4. Simulation

Simulation coding are running perfectly in line by line without any error show up. By saying, each line show each process executed in this system. Overall coding is tested in Thony simulator. In order to execute coding, Raspbian need to be running first, which included process of plug in the Raspberry Pi and virtual connection through Putty (PC) or JuiceSSH (Android). In addition, this project will planning include element Internet of Things (IoT) which bring a purpose to control the system from web server and collecting data. IoT makes the system being labelled as "Smart" system. In traditional way, this project required to switch ON manually, but with new technology of IoT, it can be switch ON from Android or Laptop which means it can done switching from anywhere [23]. Figure 5 is the flow of how IoT process implementing in the system.

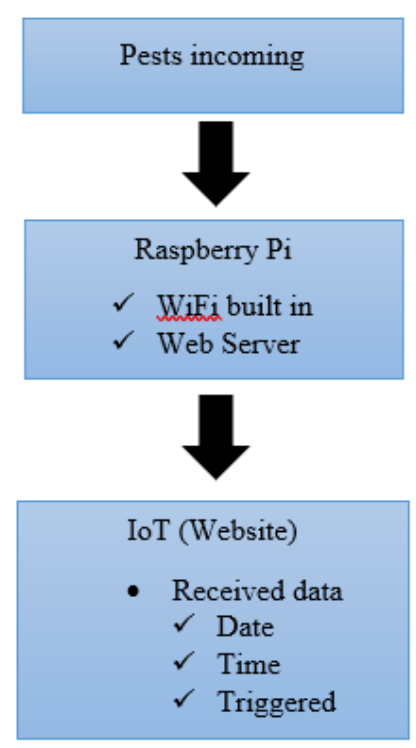

Figure 5. IoT cloud process 
Figure 6 shows the interface of IoT implementation with build a website using Apache web server installed in Raspberry Pi.

\begin{tabular}{|c|c|}
\hline \multicolumn{2}{|c|}{$\begin{array}{c}\text { IoT Intergration system } \\
\text { SMART PEST REPELLER WITH RASPBERRY PI }\end{array}$} \\
\hline \multicolumn{2}{|c|}{ SWITcH } \\
\hline Hi, please Wake Me up ! & ON \\
\hline Hey, I want to Sleep II & OFF \\
\hline \multicolumn{2}{|c|}{ Refresh new data incoming $\cdots \rightarrow$ HERE } \\
\hline
\end{tabular}

Copyrighte by Safwan

Figure 6. Project website using Apache web server

\section{CONCLUSION}

This paper presents about the smart repeller system which the objectives are successfully achieved. This system managed to detect any insects incoming towards plant by using Infrared sensor which has long range sense feature [24]. As knowing, insects bring bad effect and causes diseases which connected to human [25]. Developing this system will able to control and analysis the healthiness of plants at good level. Excessive usage of pesticide is very dangerous to the ecosystem and to the consumer. It may cause to other type of disease that could widely spread as the pesticide could travel by air and water. But not applying the pesticide also can affect the agriculture sector in production and quality of the plant. By controlling the usage of the pesticide, this will lead to higher production of food and ecosystem also healthy environment with safe to eat food to the society. This is why this project could help to manage the usage of pesticide and also able to give healthy growth for the plant. Percentage of human developing also can be determined from certain plant they consumed. Moreover, by implementing web server in this project, it help a lot in executing process. Online process made everything efficient and handy.

\section{ACKNOWLEDGEMENTS}

The authors wish to thank members of Faculty of Electrical Engineering, Universiti Teknologi MARA Shah Alam, Malaysia for the guidance and support during this project. This research was supported by "Fundamental Research Grants Scheme", file No. 600-IRMI/FRGS 5/3 (099/2017), and Minister of Higher Education.

\section{REFERENCES}

[1] L. J. Unnevehr, "Causes of and constraints to agricultural and economic development: Discussion," Am. J. Agric. Econ., vol. 89, no. 5, pp. 1168-1169, 2007.

[2] B. B. Bakar, "The Malaysian Agriculture Landscapes," Malaysian Agric. Ind. New Millenn. - Issues Challenges, no. c, pp. 337-356, 2009.

[3] I. Nakurte, "Current trends and future perspective of glyphosate use , determination and control methods in Latvia Glyphosate Is there reason for concern in," 2016."and Sustainability Goals," 2017.

[4] K. Nakayama, "Biological Image Motion Processing: A Review Multiplicity of functional roles Motion blindness? Parallel and serial processing within an early motion system: a skeletal model Intermediate values of velocity Experiments using sinusoidal gratings Common spa," Vis. Res, vol. 25, no. 5, pp. 63-660, 1985.

[5] C. R. Vaughn, W. Wolf, W. Klassen, C. R. Vaughn, W. Wolf, and W. Klassen, ",Radar, Insect Population Ecology, and Pest Management," vol. 70, 2019.

[6] S. V Gaikwad, A. N. Gaikwad, R. Harsh, and A. Gupta, "Simulation Modeling and Implementation of RF and MW System to Control the Insect Pests in Agriculture," no. 6, pp. 6-9, 2015.

[7] B. O. Flynn, M. De Donno, C. Barrett, C. Robinson, A. O. Riordan, and A. E. M. Sensors, "Smart Microneedle Sensing Systems for Security in Agriculture , Food and the Environment ( SAFE )."

[8] J. L. E. Honrado, D. B. Solpico, C. M. Favila, E. Tongson, G. L. Tangonan, and N. J. C. Libatique, "UAV Imaging with Low-cost Multispectral Imaging System for Precision Agriculture Applications," 2017.

[9] K. Li, L. Xiong, D. Zhang, Z. Liang, and Y. Xue, "The Research of Disease Spots Extraction Based on Evolutionary Algorithm,” vol. 2017, 2017. 
[10] J. Kundu, S. Debi, S. Ahmed, and S. Halder, "Smart E-Agriculture Monitoring System: Case Study of Bangladesh," pp. 28-30, 2017.

[11] H. Ri et al., "\$ IIRUGDEOH ) LHOG ( QYLURQPHQWDO ORQLWRULQJ DQG 3ODQW * URZWK 0HDVXUHPHQW 6 \VWHP IRU 6PDUW \$ JULFXOWXUH,” pp. 7-10, 2017.

[12] L. Hongli, Y. Zhoumiqi, Z. Jinshui, and G. Shuai, "Highly Efficient Paddy Classification Using Uav-Based Orthorectified Image College of Resources Science and Technology/Skate Key Laboratory of Earth Surface Processes and Resource Ecology, Beijing Normal University, Beijing 100875, China Department o,” pp. 1-4.

[13] M. S. Mekala, "A Survey: Smart Agriculture IoT with Cloud Computing," 2017.

[14] J. L. Hill, "System Architecture for Wireless Sensor Networks by," 2003.

[15] K. C. Sahoo and K.- Pir, "IoT Based Intrusion Detection System Using PIR Sensor," pp. 1641-1645, 2017.

[16] E. Sarajevo, "Raspberry Pi as a Wireless Sensor Node : Performances and Constraints," no. May, pp. 26-30, 2014.

[17] M. Ibrahim, A. Elgamri, S. Babiker, and A. Mohamed, "Monitoring using the Raspberry-Pi Computer," pp. 159-164, 2015.

[18] K. Lokesh Krishna, O. Silver, W. F. Malende, and K. Anuradha, "Internet of Things application for implementation of smart agriculture system,” Proc. Int. Conf. IoT Soc. Mobile, Anal. Cloud, I-SMAC 2017, pp. 54-59, 2017.

[19] R. S. Drabman, D. L. Creedon, and H. C. Features Submission, "Beat the Buzzer," Child Behav. Ther., vol. 1, no. 3, pp. 295-296, 2011.

[20] S. D. Kale, S. V Khandagale, S. S. Gaikwad, S. S. Narve, and P. V Gangal, "Agriculture Drone for Spraying Fertilizer and Pesticides,” Int. J. Adv. Res. inComputer Sci. Softw. Eng., vol. 5, no. 12, pp. 804-807, 2015.

[21] J. Hao and T. K. Ho, “ Machine Learning Made Easy: A Review of Scikit-learn Package in Python Programming Language," J. Educ. Behav. Stat., vol. 44, no. 3, pp. 348-361, 2019.

[22] J. Muangprathub, N. Boonnam, S. Kajornkasirat, N. Lekbangpong, A. Wanichsombat, and P. Nillaor, "IoT and agriculture data analysis for smart farm," Comput. Electron. Agric., vol. 156, no. December 2018, pp. 467-474, 2019.

[23] L. Jiao, M. Chen, X. Wang, X. Du, and D. Dong, "Monitoring the number and size of pests based on modulated infrared beam sensing technology," Precis. Agric., vol. 19, no. 6, pp. 1100-1112, 2018.

[24] C. Colosio, F. M. Rubino, and A. Moretto, "Pesticides," Int. Encycl. Public Heal., vol. 1, pp. 454-462, 2016.

\section{BIOGRAPHIES OF AUTHORS}
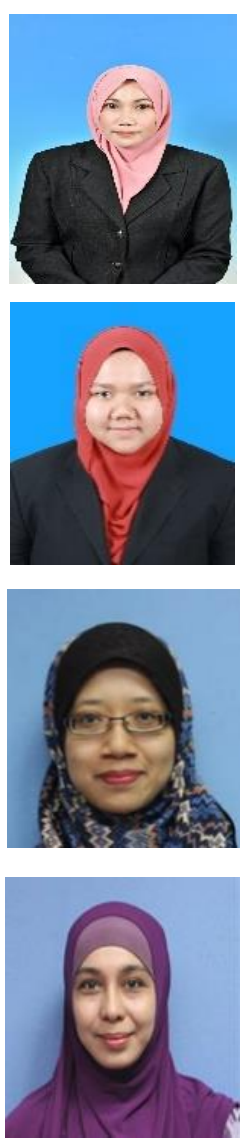

Suzi Seroja Sarnin received her Bachelor of Electrical and Electronics (B.Eng), in field of Communication from the Universiti Teknologi Malaysia, Skudai, in 1999. She completed her Master of Microelectronics (Msc), from the Universiti Kebangsaan Malaysia in 2005. She has a $\mathrm{PhD}$ of Electrical Engineering from Universiti Teknologi MARA, Shah Alam, Malaysia, in 2019. As a senior lecturer at Universiti Teknologi MARA she has collaborated actively with another researcher in several other disciplines of Electrical Engineering. Her current research interests are in the area of wireless communication and Internet of Things.

Nur Jumaatul Hidayati Bt Mohammad was born in Pahang, Malaysia On 2 February 1996. Finish the Diploma in electrical engineering in UITM Dungun Terengganu for 2(1/2) years (20142016).Currently doing Degree in Electrical engineering majoring in communication until now.

Nani Fadzlina Naim received the B.Eng. degree in Electrical and Electronics Engineering and M.Eng degree in Electronics and Communication Engineering from Universiti Teknologi Malaysia (UTM) in 2005 and 2007, respectively. She received her PhD in 2015 in Electrical, Electronics and Systems Engineering from Universiti Kebangsaan Malaysia (UKM). She is currently a senior lecturer at Faculty of Electrical Engineering, Universiti Teknologi MARA (UiTM). Her current research interests are in the area of optical networks design, optical network monitoring, Fiber Bragg Grating, optical sensing technology and its application.

Norsuzila Ya'acob was born at Terengganu, Malaysia on 20 March 1972. In 2010, she was awarded a $\mathrm{PhD}$ degree in electrical, electronic \& systems engineering from Universiti Kebangsaan Malaysia (UKM), Selangor, Malaysia for a work on modeling and determination of ionosphere effects to improve GPS system accuracy. She also obtained her M.Sc degree from Universiti Putra Malaysia (UPM), Selangor, Malaysia in remote sensing and geographic information systems in 2000. Previously, she obtained her B.Eng degree from Universiti Putra Malaysia (UPM), Selangor, Malaysia in electronics \& computer engineering in 1999. 